\title{
Regulation of histidine-rich glycoprotein (HRG) function via plasmin-mediated proteolytic cleavage
}

\author{
Ivan K. H. POON ${ }^{\star} \dagger$, Anna-Karin OLSSON $\ddagger$, Mark D. HULETT ${ }^{\star} \dagger^{-1}$ and Christopher R. PARISH ${ }^{\star 1,2}$ \\ *The John Curtin School of Medical Research, Australian National University, Canberra, ACT 2601, Australia, † Department of Biochemistry, La Trobe University, Melbourne, SA 3086, \\ Australia, and $\ddagger$ Department of Medical Biochemistry and Microbiology, Uppsala Biomedical Center, Uppsala University, SE-75123 Uppsala, Sweden
}

\begin{abstract}
The plasminogen/plasmin system is involved in a variety of normal physiological and pathological processes, including tissue remodelling, angiogenesis and tumour metastasis. Plasminogen activators and receptors for plasminogen/plasminogen activators are essential for the processing of plasminogen to form the active serine protease plasmin. Plasmin can in turn positively or negatively regulate further plasminogen activation via plasminmediated cleavage of receptors and activators. HRG (histidinerich glycoprotein), a relatively abundant (approx. 100-150 $\mu \mathrm{g} / \mathrm{ml}$ ) plasma glycoprotein, has a multi-domain structure that can interact with many ligands, including $\mathrm{Zn}^{2+}$, heparin, HS (heparan sulfate) and plasminogen. HRG has been shown to function as an adaptor molecule to tether plasminogen to GAG (glycosaminoglycan)-bearing surfaces and to regulate plasminogen activation via various mechanisms. As HRG itself is sensitive to plasmin cleavage, the present study examines in detail the cleavage of
\end{abstract}

human HRG by plasmin and the effect of this cleavage on various functions of HRG. HRG fragments, generated by plasmin cleavage, are held together by disulfide linkages and are not released from the molecule under non-reducing conditions. Plasmin-mediated cleavage partially inhibited HRG binding to cell surface HS, but enhanced HRG binding to necrotic cells and to plasminogen. However, both intact and plasmin-cleaved HRG enhanced the binding of plasminogen to heparin-coated surfaces to a similar extent. Furthermore, the presence of heparin, $\mathrm{Zn}^{2+}$ or acidic $\mathrm{pH}$ was found to protect HRG from plasmin cleavage. Thus proteolytic cleavage of HRG by plasmin may provide a feedback mechanism to regulate the effects of HRG on the plasminogen/plasmin system and other functions of HRG.

Key words: heparan sulfate (HS), histidine-rich glycoprotein (HRG), plasmin, plasminogen, proteolytic cleavage.

\section{INTRODUCTION}

Serum protein-based biological systems, such as the complement, coagulation and fibrinolytic pathways, often rely heavily on the proteolytic cleavage of serum proteins to regulate successive enzymatic cascades or to generate specific protein fragments that can perform various functions. In particular, the plasminogen/ plasmin system, which plays an important role in the dissolution of fibrin clots and remodelling of the ECM (extracellular matrix), utilizes a variety of proteolytic cleavage-based mechanisms to either positively or negatively regulate the formation of the serine protease plasmin from its zymogen plasminogen [1]. Briefly, plasmin is formed via the proteolytic processing of the plasma zymogen plasminogen by activators such as urokinase-type or tissue-type plasminogen activators (u-PA or t-PA) [1]. Plasmin can in turn regulate plasminogen activation via a number of different mechanisms, namely: (i) plasmin-mediated cleavage of single chain u-PA and t-PA to generate a more active twochain enzyme [2,3]; (ii) proteolytic cleavage of fibrin by plasmin to expose C-terminal lysine residues that enhance plasminogen binding to fibrin and activation by t-PA [4]; and (iii) plasminmediated cleavage of the $\mathrm{u}-\mathrm{PAR}$ ( $\mathrm{u}-\mathrm{PA}$ receptor) to reduce the cell surface localization of $\mathrm{u}-\mathrm{PA}$ for plasminogen activation [5].

HRG (histidine-rich glycoprotein) is a secreted singlepolypeptide-chain protein, with a molecular mass of approx. $75 \mathrm{kDa}$, that is found in human plasma at the relatively high concentration of approx. 100-150 $\mu \mathrm{g} / \mathrm{ml}$ [6]. HRG has a multidomain structure consisting of two N-terminal regions with homology with cystatin-like domains, together termed the N1N2 domain, a central HRR (histidine-rich region), flanked by two PRRs (proline-rich regions; PRR1 and PRR2), and a C-terminal domain [6]. HRG also contains four intra-domain and two interdomain disulfide bridges that link the C-terminal domain and the HRR to the N1N2 domain [7]. There are many ligands of $\mathrm{HRG}$, such as $\mathrm{Zn}^{2+}$, haemin, heparin, HS (heparan sulfate), IgG and fibrinogen [6,8], with HRG also interacting strongly with the lysine-binding sites on plasminogen [9], possibly via its C-terminal lysine residues [10,11]. Initially, HRG was proposed to be an anti-fibrinolytic agent, acting by blocking plasminogen from interacting with binding partners that are important for plasmin activation [9], such as fibrinogen, fibrin, integrin $\alpha_{\mathrm{M}} \beta_{2}$ and annexin 2 [1]. However, there are conflicting reports in this area with different studies demonstrating that HRG either inhibits, or has no effect on, fibrinogen-dependent plasminogen activation [12,13]. In stark contrast, HRG has been suggested to function as a soluble plasminogen receptor that aids plasminogen activation by tethering plasminogen to GAG (glycosaminoglycan)-coated surfaces [12] and to cell surfaces [14].

Human HRG has been shown to be susceptible to proteolytic cleavage in vitro by serine proteases, such as plasmin and kallikrein, but not thrombin [15]. Extensive proteolysis of human HRG has also been observed in patients that have received streptokinase therapy, which increases plasmin activity in vivo

Abbreviations used: $\mathrm{CHO}$, Chinese-hamster ovary; ECM, extracellular matrix; FGF, fibroblast growth factor; GAG, glycosaminoglycan; HRG, histidinerich glycoprotein; HRR, histidine-rich region of HRG; HRP, horseradish peroxidase; HS, heparan sulfate; N1N2, the N-terminal domains of HRG; Ni-NTA, $\mathrm{Ni}^{2+}$-nitrilotriacetic acid; PE, phycoerythrin; PRR, proline-rich region of HRG; t-PA, tissue-type plasminogen activator; u-PA, urokinase-type plasminogen activator.

1 These authors contributed equally to this work.

2 To whom correspondence should be addressed (email Christopher.Parish@anu.edu.au). 
[15]. Furthermore, the ability of plasmin to cleave HRG at specific sites between different domains of the molecule has been utilized to isolate various intact domains of HRG and characterize their structure and function, with rabbit HRG having been studied in some detail [10,16-18]. Although the release of the HRR of HRG following plasmin cleavage was suggested to play an important role in mediating the anti-angiogenic [19], and possibly the antimicrobial, effects of the molecule [20], the physiological significance of plasmin-mediated cleavage of human $\mathrm{HRG}$ has not been thoroughly examined. To this end, in the present study human HRG was proteolytically cleaved by plasmin, a treatment that generated HRG fragments that are held together by disulfide bonds. Although initial plasmin treatment did not release any HRG fragments under non-reducing conditions, plasmin-mediated cleavage partially reduced HRG binding to cell surface HS and potentiated HRG binding to necrotic cells and to plasminogen. However, plasmin cleavage had no major effect on the ability of HRG to tether plasminogen to heparin-coated surfaces. In addition, the presence of heparin, $\mathrm{Zn}^{2+}$ or acidic $\mathrm{pH}$ was found to protect HRG from plasmin cleavage. Therefore, proteolytic cleavage of HRG by plasmin may play an important role in regulating HRG function.

\section{EXPERIMENTAL}

\section{Antibodies and reagents}

An N1N2-domain specific anti-(human HRG) monoclonal antibody, HRG-4, was provided by AGEN Biomedical. Domainspecific rabbit anti-(human $\mathrm{HRG}$ ) antibodies (0115, 0116 and 0119) were produced in-house as previously described [19]. The use of animals to generate domain-specific rabbit anti-(human HRG) antibodies was approved by the Uppsala University. Rabbit anti-(human plasminogen) antibody was supplied by Dako. Sheep anti-mouse Ig-HRP (horseradish peroxidase) antibody, sheep anti-rabbit Ig-HRP antibody, sheep $\mathrm{F}\left(\mathrm{ab}^{\prime}\right)_{2}$ anti-mouse IgFITC antibody and sheep $\mathrm{F}\left(\mathrm{ab}^{\prime}\right)_{2}$ anti-mouse Ig-PE (phycoerythrin) antibody were purchased from Chemicon and Ni-NTA $\left(\mathrm{Ni}^{2+}\right.$-nitrilotriacetate)-HRP was purchased from Kirkegaard and Perry Laboratories. Human plasminogen and biotinylated heparin were gifts from Dr Allison Jones and Dr Craig Freeman (The John Curtin School of Medical Research, Australian National University, Canberra, Australia) respectively. BSA, ExtrAvidin ${ }^{\circledR}$, bovine lung heparin and human plasmin were purchased from Sigma-Aldrich.

\section{Cell lines}

The GAG-bearing $\mathrm{CHO}$ (Chinese-hamster ovary)-K1 and the GAG-deficient CHO pgsA-745 cell lines were cultured in 50\% Dulbecco's modified Eagle's medium and 50\% Ham's nutrient mixture F-12 (Invitrogen). Jurkat T-cells were cultured in RPMI1640 medium (Invitrogen). All mammalian cell culture media were supplemented with $10 \%(\mathrm{v} / \mathrm{v})$ fetal calf serum, $5 \mathrm{mM}$ L-glutamine, $30 \mu \mathrm{g} / \mathrm{ml}$ penicillin $\mathrm{G}, 50 \mu \mathrm{g} / \mathrm{ml}$ streptomycin sulfate and $50 \mu \mathrm{g} / \mathrm{ml}$ neomycin sulfate. Mammalian cell lines were incubated at $37^{\circ} \mathrm{C}$ in a humidified atmosphere containing $5 \% \mathrm{CO}_{2}$. To generate primary necrotic cells, Jurkat T-cells were resuspended at a concentration of $2 \times 10^{6}$ cells $/ \mathrm{ml}$ and exposed to hyperthermic conditions $\left(56^{\circ} \mathrm{C}\right)$ for $30 \mathrm{~min}$.

\section{Purification of human plasma-derived HRG}

HRG was purified from human plasma according to a previously described method $[21,22]$. The use of human plasma was approved by the Australian Red Cross Blood Service, the Australian National University and La Trobe University. Briefly, human plasma was passed through a phosphocellulose column (Whatman) equilibrated with a solution containing $0.5 \mathrm{M} \mathrm{NaCl}$, $10 \mathrm{mM}$ sodium phosphate buffer and $1 \mathrm{mM}$ EDTA at pH 6.8. Bound HRG was eluted with a solution containing $2.0 \mathrm{M}$ $\mathrm{NaCl}, 10 \mathrm{mM}$ sodium phosphate buffer and $1 \mathrm{mM}$ EDTA at $\mathrm{pH}$ 6.8. Traces of human IgG were removed by passing plasmaderived HRG through a HiTrap ${ }^{\mathrm{TM}}$ Protein G column (Amersham Biosciences).

\section{Generation of plasmin-cleaved HRG}

Plasmin-cleaved HRG used in the present study was generated via the same procedure with minor modifications, depending on the application. For the initial analysis of the proteolytic cleavage of HRG by plasmin and the preparation of samples for Edman $\mathrm{N}$-terminal sequencing, plasmin-mediated digestion of HRG was performed at $37^{\circ} \mathrm{C}$ using $1 \mathrm{mg} / \mathrm{ml} \mathrm{HRG}$ and $50 \mu \mathrm{g} / \mathrm{ml}$ plasmin in PBS (pH 7.2). To examine plasmin-mediated cleavage of HRG ex vivo, $1 \mu \mathrm{l}$ of human plasma was diluted to $10 \mu \mathrm{l}$ in $\mathrm{PBS}$ ( $\mathrm{pH} 7.2$ ) containing 1,3 and $9 \mu \mathrm{g}$ of plasmin and then incubated at $37^{\circ} \mathrm{C}$ for $120 \mathrm{~min}$. For ELISA- and flow cytometry-based binding assays and Western blot analysis using the HRG-4 N1N2-domain specific anti-(human HRG) antibody, proteolytic cleavage of HRG was performed at $37^{\circ} \mathrm{C}$ using $300 \mu \mathrm{g} / \mathrm{ml} \mathrm{HRG}$ and $30 \mu \mathrm{g} / \mathrm{ml}$ plasmin in PBS (pH 7.2). Following plasmin treatment, $\mathrm{HRG}$ preparations were diluted in appropriate buffer containing $50 \mu \mathrm{g} / \mathrm{ml}$ aprotinin (Boehringer) to inhibit further digestion of HRG by plasmin during the subsequent binding assay. To investigate the effect of heparin $(12.5 \mathrm{kDa}), \mathrm{pH}$ and $\mathrm{Zn}^{2+}$ on the proteolytic cleavage of HRG by plasmin, $30 \mu \mathrm{g} / \mathrm{ml} \mathrm{HRG} \mathrm{and} 6 \mu \mathrm{g} / \mathrm{ml}$ plasmin were diluted in PBS and incubated at $37^{\circ} \mathrm{C}$ for $60 \mathrm{~min}$ under the different conditions.

\section{SDS/PAGE and Coomassie Brilliant Blue protein staining}

Protein samples were boiled in reducing or non-reducing SDS sample buffer [125 mM Tris/HCl, pH 6.8, containing $20 \%(\mathrm{v} / \mathrm{v})$ glycerol, $4 \%(\mathrm{w} / \mathrm{v}) \mathrm{SDS}$, with the reducing buffer containing $50 \mathrm{mM}$ dithiothreitol. Samples were subjected to PAGE on a 4$20 \%$ (w/v) gradient gel (Gradipore). Unless otherwise stated, all samples were subjected to SDS/PAGE under reducing conditions. Protein samples were subsequently stained with Coomassie Brilliant Blue $[0.2 \%$ Coomassie Brilliant Blue, $50 \%$ (v/v) methanol, $7.5 \%(\mathrm{v} / \mathrm{v})$ acetic acid] and then destained with destaining buffer $[40 \%(\mathrm{v} / \mathrm{v})$ methanol, $7 \%(\mathrm{v} / \mathrm{v})$ acetic acid].

\section{N-terminal sequencing}

Following SDS/PAGE and Coomassie Brilliant Blue staining, selected protein bands were excised from the polyacrylamide gel and subjected to Edman N-terminal sequencing (performed by the Australian Proteome Analysis Facility).

\section{Western blotting}

Following SDS/PAGE, protein samples were transferred electrophoretically from the polyacrylamide gel on to a nitrocellulose membrane (Amersham Biosciences) using a Mini-Protean II apparatus (Bio-Rad) in transfer buffer containing $25 \mathrm{mM}$ Tris base, $192 \mathrm{mM}$ glycine and $20 \%$ (v/v) methanol. The membrane was blocked for $16 \mathrm{~h}$ at $4{ }^{\circ} \mathrm{C}$ with $5 \%(\mathrm{w} / \mathrm{v})$ skimmed milk powder diluted in PBS. Intact and plasmin-cleaved HRG were detected using domain-specific mouse and rabbit anti-(human HRG) antibodies and Ni-NTA-HRP and by chemiluminescence 
using $\mathrm{ECL}^{\circledR}$ (enhanced chemiluminescence) Western blotting detection reagents (GE Healthcare).

\section{Enzyme-linked immunoabsorbent assay}

ELISAs were performed by coating U-bottomed 96-well microtitre plates (Dynex) with the protein to be immobilized in PBS for $16 \mathrm{~h}$ at $4{ }^{\circ} \mathrm{C}$. Plates were washed with PBS containing $0.02 \%$ Tween-20 and then incubated with PBS containing $3 \%$ (w/v) BSA for $3 \mathrm{~h}$ at $4{ }^{\circ} \mathrm{C}$ to block non-specific binding. In some experiments $10 \mu \mathrm{g} / \mathrm{ml}$ biotinylated heparin, diluted in PBS conataining $1 \%$ (w/v) BSA, was added to $10 \mu \mathrm{g} / \mathrm{ml}$ ExtrAvidin ${ }^{\circledR}$-coated plates for $90 \mathrm{~min}$ at $4{ }^{\circ} \mathrm{C}$ prior to addition of PBS containing $3 \%(\mathrm{w} / \mathrm{v})$ BSA. Binding proteins diluted in PBS containing $1 \%(\mathrm{w} / \mathrm{v})$ BSA were then added and the plates incubated for $90 \mathrm{~min}$ at $4{ }^{\circ} \mathrm{C}$. Plate-bound $\mathrm{HRG}$ and plasminogen were detected using the HRG-4 N1N2-domain specific antibody and a rabbit anti-(human plasminogen) antibody respectively, followed by secondary antibody detection with HRP-conjugated antibodies. Plate-bound HRP was detected using a peroxidase substrate (Kirkegaard and Perry Laboratories). The absorbance of the enzymatic product at $405 \mathrm{~nm}$ was measured using a Thermomax microplate reader (Molecular Devices). The results were analysed using SoftMaxPro 4.0 software (Molecular Devices).

\section{Immunofluorescence flow cytometry}

Viable and necrotic cells were analysed for HRG binding by immunofluorescence flow cytometry. Typically, $2 \times 10^{5}$ cells were incubated with $100 \mu \mathrm{g} / \mathrm{ml}$ intact or plasmin-cleaved $\mathrm{HRG}$ diluted in PBS containing $0.1 \%$ BSA ( $\mathrm{pH} 6.6$ or $\mathrm{pH} 7.2$ ), with or without $\mathrm{Zn}^{2+}$, for $30 \mathrm{~min}$ at $4{ }^{\circ} \mathrm{C}$. Cells were washed three times with PBS containing $0.1 \%$ BSA ( $\mathrm{pH} 7.2$ ) and then cell-bound HRG was detected using the HRG-4 N1N2-domain specific antibody, followed by secondary antibody detection with FITC- or PEconjugated antibodies. Cells were resuspended in PBS, pH 7.2, containing $0.1 \%$ BSA and $1 \mu \mathrm{g} / \mathrm{ml}$ Hoechst 33258 (Calbiochem) and immediately analysed by immunofluorescence flow cytometry using a LSR1 Flow Cytometer and Cell Quest Pro software (BD Biosciences). The resultant flow cytometry results were analysed using FlowJo software (Tree Star). Cells treated in the same manner in the absence of binding proteins were used as negative controls to set up appropriate laser voltage. Cells were gated appropriately based on forward and side scattering. Living and dead cells were distinguished on the basis of Hoechst 33258 negative and positive staining respectively.

\section{Plasmin activity assay}

The chromogenic plasmin substrate $N$-(p-tosyl)-Gly-Pro-Lys (Sigma-Aldrich) was used to assess plasmin activity. Briefly, samples were prepared in $50 \mu \mathrm{l}$ of PBS (pH 7.2, 6.6 or 6.0) containing $1 \mathrm{mg} / \mathrm{ml} N$-( $p$-tosyl)-Gly-Pro-Lys and incubated for $60 \mathrm{~min}$ at $37^{\circ} \mathrm{C}$. Samples were then transferred into a Ubottomed 96-well microtitre plate and the absorbance of the enzymatic product was measured at $405 \mathrm{~nm}$ on a Thermomax microplate reader. Results were analysed using SoftMaxPro 4.0 software.

\section{RESULTS}

\section{Proteolytic cleavage of human HRG by plasmin}

As the plasmin cleavage sites in human HRG have not been defined, the ability of plasmin to cleave human HRG was initially examined by SDS/PAGE under both non-reducing and reducing conditions. Under non-reducing conditions, plasmin-cleaved (30$120 \mathrm{~min}$ at $37^{\circ} \mathrm{C}$ ) $\mathrm{HRG}$ showed no major decrease in molecular mass compared with untreated (0 min) HRG, whereas multiple protein bands were observed under reducing conditions with plasmin-cleaved but not with untreated HRG (Figure 1A). These results demonstrate that plasmin can effectively cleave human HRG at multiple sites with a cleavage pattern similar to that previously described for rabbit HRG [16] and human HRG [15] when analysed by SDS/PAGE under reducing conditions. In addition, plasmin-cleaved fragments of HRG remain predominately bound together by disulfide bonds and are not released from the rest of the molecule under non-reducing conditions. However, it is worth noting that under non-reducing conditions a small proportion of the HRG subjected to the extensive plasmin-cleavage $\left(120 \mathrm{~min}\right.$ at $\left.37^{\circ} \mathrm{C}\right)$ showed a clear reduction in molecular mass compared with the untreated HRG (Figure 1A). These results suggest that certain plasmin-generated fragments of HRG are not linked to the rest of the molecule via disulfide bonds and can be released from HRG under nonreducing conditions, although such fragments are only generated following prolonged plasmin treatment. Furthermore, proteolytic cleavage of HRG can also occur in human plasma ex vivo by the addition of exogenous plasmin (Figure 1B), indicating that an increase in plasmin activity in plasma can generate plasmincleaved fragments of HRG.

To determine the domains of HRG that are present in each fragment of plasmin-cleaved HRG, domain-specific rabbit anti(human HRG) antibodies (0115, 0116 and 0119) were used to detect intact and plasmin-cleaved HRG under reducing conditions by Western blot analysis. As shown in Figure 1(C), the N-terminalspecific anti-(human HRG) antibody (0116) bound strongly to intact $\mathrm{HRG}$ and plasmin-cleaved $\mathrm{HRG}$ fragments that are $\sim 37 \mathrm{kDa}$ or above, indicating that all these fragments contain the N-terminal domain of HRG. It is worth noting that these $\mathrm{N}$-terminal fragments of HRG appear to migrate as doublets on SDS/PAGE under reducing conditions (Figure 1C), possibly representing different glycoforms of HRG. Moreover, the HRRspecific anti-(human HRG) antibody (0119) only detected intact HRG and the largest plasmin-cleaved HRG fragment of $\sim 60 \mathrm{kDa}$, indicating that the epitope recognized by the HRR-specific anti(human HRG) antibody (0119) is absent in all the other plasmincleaved HRG fragments (Figure 1C). Similarly, the C-terminalspecific anti-human HRG antibody (0115) detected intact HRG and the $\sim 12 \mathrm{kDa}$ fragment (Figure 1C), indicating that the $12 \mathrm{kDa}$ plasmin-cleaved HRG fragment contains the C-terminal domain.

The proteolytic cleavage of human HRG by plasmin was further investigated by Edman N-terminal sequence analysis of intact and selected plasmin-cleaved HRG fragments acquired under reducing conditions, in order to define the plasmin cleavage sites and predict the domains of HRG present in the fragment of interest. Consistent with the antibody-binding results (Figure 1C), and with previous studies on rabbit HRG [16], the N-terminal sequence of intact and the $\sim 37 \mathrm{kDa}$ fragment of $\mathrm{HRG}$ was identical (Figure 2A), suggesting that all plasmin-cleaved HRG fragments above $37 \mathrm{kDa}$ are likely to contain the same $\mathrm{N}$-terminus and each successive fragment from 75 to $37 \mathrm{kDa}$ represents progressive plasmin-mediated cleavage of $\mathrm{HRG}$ from the C-terminus. The $\sim 12 \mathrm{kDa}$ fragment that was released after plasmin treatment of $\mathrm{HRG}$ at $37^{\circ} \mathrm{C}$ for $30 \mathrm{~min}$ contains an N-terminal sequence of RRGPGKG (Figure 2A), indicating a plasmin cleavage site on the carboxy side of $\mathrm{Arg}^{421}$ and therefore this fragment contains the C-terminal domain and parts of the PRR2 of HRG (see Supplementary Figure S1, available at http://www.BiochemJ. 
A

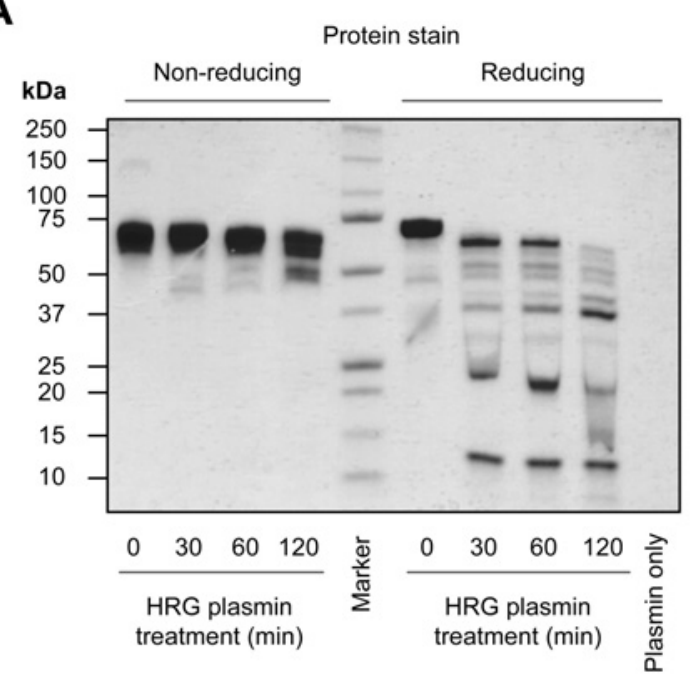

B

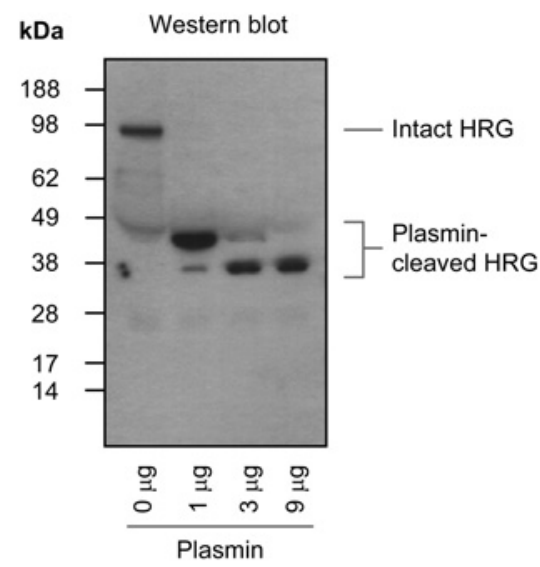

C

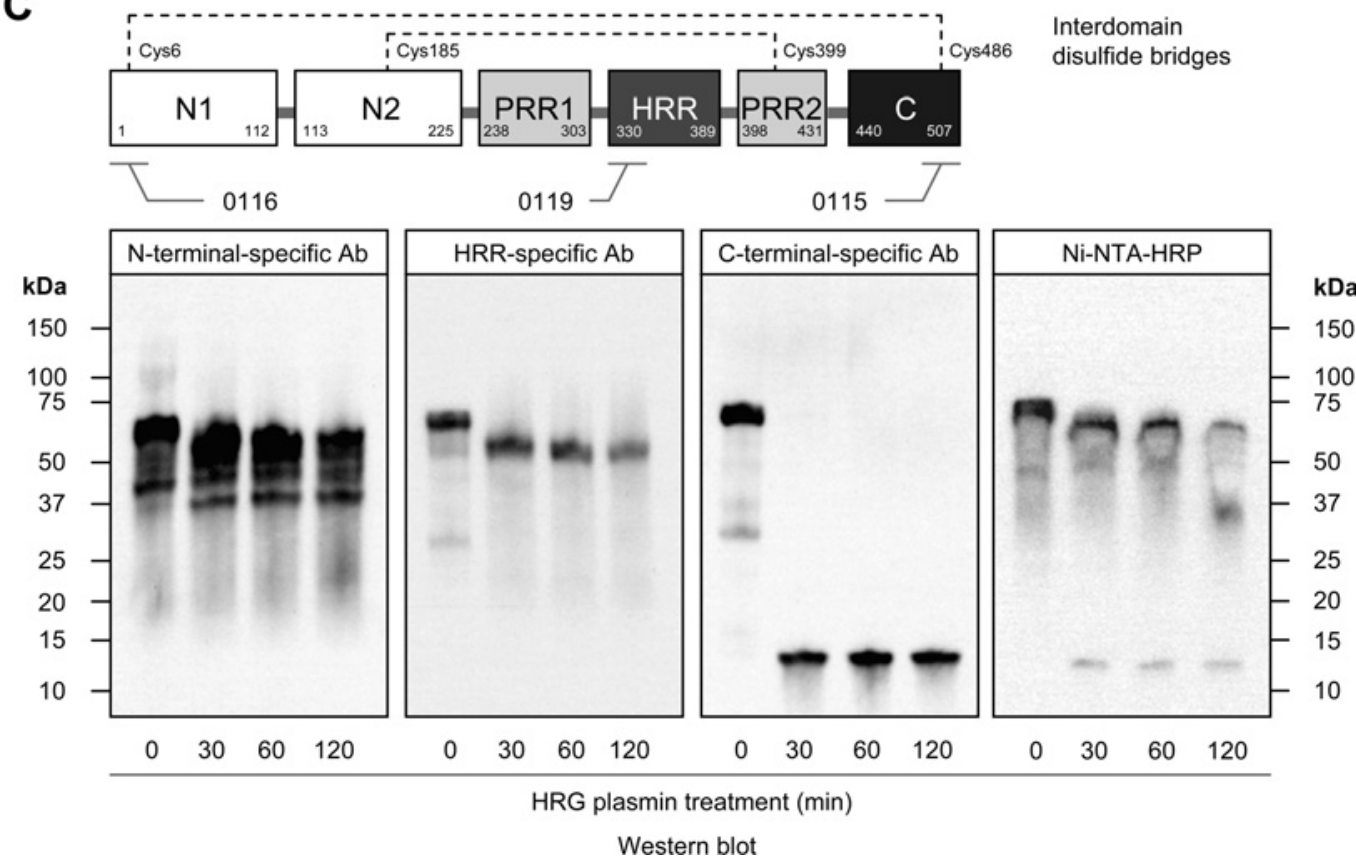

Interdomain disulfide bridges

Figure 1 Determination of the plasmin-cleaved fragments of human HRG

(A) SDS/PAGE analysis of the proteolysis of HRG (10 $\mu \mathrm{g}, 1 \mathrm{mg} / \mathrm{ml})$ by plasmin $(0.5 \mu \mathrm{g}, 50 \mu \mathrm{g} / \mathrm{ml})$ at $37^{\circ} \mathrm{C}$ for $0,30,60$ and $120 \mathrm{~min}$ in the presence (Reducing) or absence (Non-reducing) of dithiothreitol, with plasmin alone being included as a negative control. Protein bands stained with $0.2 \%$ Coomassie Brilliant Blue. (B) Western blot analysis of the proteolysis of HRG in $1 \mu$ l human plasma by 1,3 and $9 \mu \mathrm{g}$ exogenous plasmin at $37^{\circ} \mathrm{C}$ for 120 min using monoclonal HRG-4 anti-(human HRG) antibody, specific to the N1N2 domain. (C) Western blot analysis of the proteolysis of HRG $(750 \mathrm{ng}, 1 \mathrm{mg} / \mathrm{ml})$ by plasmin $(37.5 \mathrm{ng}, 50 \mu \mathrm{g} / \mathrm{ml})$ at $37^{\circ} \mathrm{C}$ for $0,30,60$ and $120 \mathrm{~min}$ using the domain-specific rabbit anti-(human HRG) antibodies 0115,0116 and 0119. The specificity of each antibody is shown schematically in the upper panel. N1, N-terminal domain 1; N2, N-terminal domain 2; PRR1, proline-rich region 1; HRR, histidine-rich region; PRR2, proline-rich region 2; C, C-terminal domain. Histidine-rich sequences present in $3 \mu \mathrm{g}$ of intact and plasmin-cleaved HRG were also detected using HRP-conjugated Ni-NTA (Ni-NTA-HRP).

org/bj/424/bj4240027add.htm, for the amino acid sequence of human HRG). Although no conclusive N-terminal sequence was obtained from the $\sim 20 \mathrm{kDa}$ plasmin-cleaved $\mathrm{HRG}$ fragment, histidine was found to be the most abundant amino acid in the first Edman sequencing cycle, followed by glycine, leucine and proline (Figure 2A). These results suggest that the $\sim 20 \mathrm{kDa}$ fragment probably contains the HRR domain and has a frayed $\mathrm{N}$-terminus. Furthermore, the presence of a frayed N-terminus in this $\sim 20 \mathrm{kDa}$ fragment could potentially disrupt the epitope recognized by the HRR-specific anti-(human $H R G$ ) antibody (0119) (Figure 1C). These results are consistent with the presence of multiple internal plasmin cleavage sites within the HRR, and hence the difficulties encountered in isolating different domains of human HRG following plasmin digestion [17]. To validate whether the $\sim 20 \mathrm{kDa}$ fragment contains the HRR of HRG, NiNTA-HRP was used to detect histidine-rich sequences present in various cleaved fragments of HRG. Surprisingly, similar to the HRR-specific anti-human HRG antibody (0119), Ni-NTAHRP was found to bind predominately to intact HRG and the largest plasmin-cleaved HRG fragment of $\sim 60 \mathrm{kDa}$, but not the $\sim 20 \mathrm{kDa}$ fragment (Figure 1C). Thus the present study cannot determine whether the $\sim 20 \mathrm{kDa}$ fragment contains the HRR 
A

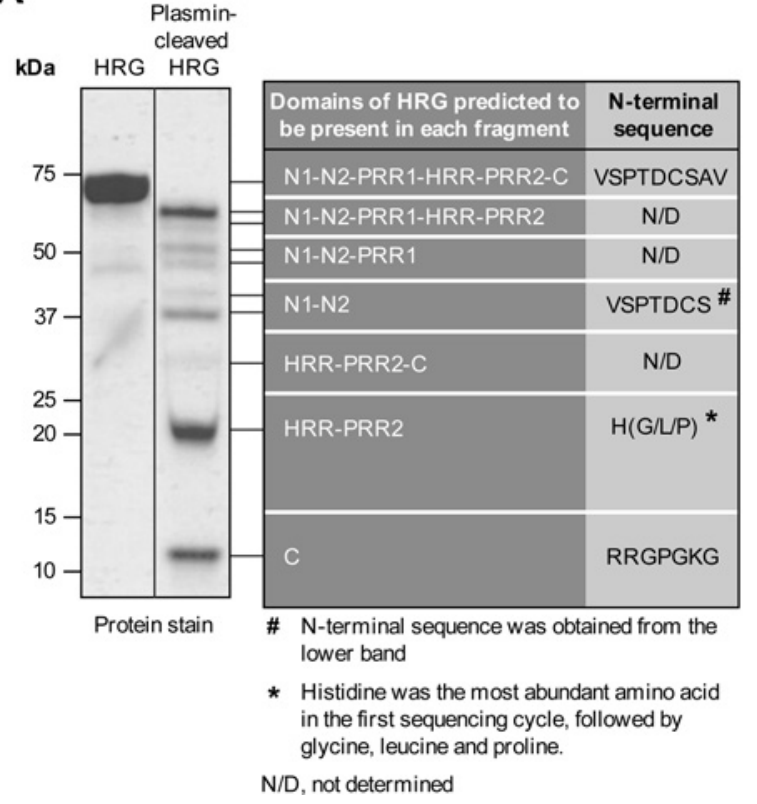

B

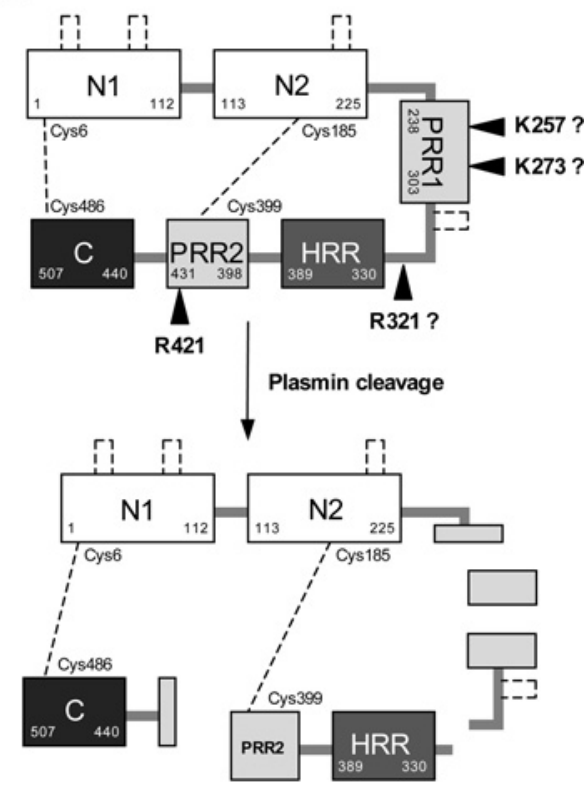

Figure 2 Determination of plasmin cleavage sites in human HRG by $\mathrm{N}$-terminal sequencing

HRG was subjected to plasmin cleavage as in Figure 1(A). (A) N-terminal amino acid sequence analysis of intact and plasmin-cleaved HRG fragments obtained under reducing conditions. Edman $\mathrm{N}$-terminal sequencing results for each HRG fragment are indicated in the Figure corresponding to the results acquired in Figure $1(\mathrm{~A})$. On the basis of the $\mathrm{N}$-terminal sequencing results and domain-specific antibody and Ni-NTA binding results in Figure 1(B), domains of HRG predicted to be present in each HRG fragment are also indicated. (B) Schematic representation of the proteolysis of human HRG by plasmin, with black triangle indicating potential plasmin cleavage sites. N1, N-terminal domain 1; N2, N-terminal domain 2; PRR1, proline-rich region 1; HRR, histidine-rich region; PRR2, proline-rich region 2; C, C-terminal domain.

of HRG. Furthermore, it is worth noting that a faint band was also detected at $\sim 30 \mathrm{kDa}$ under reducing conditions (Figure 1A). However, owing to the low yield of this fragment, its N-terminal sequence was not determined. Nevertheless, as the HRR- and C-terminal-specific anti-(human HRG) antibodies (0119 and 0115 ) were both able to recognize the $\sim 30 \mathrm{kDa}$ fragment (Figure 1C), this fragment may contain the HRR and C-terminal domain of HRG (Figure 2A). Therefore based on the results in the present paper, and previous studies on rabbit HRG [16,17] and human HRG [19], the predicted outcome of plasmin-mediated cleavage of HRG is shown in Figure 2(B).

In order to monitor the effect of plasmin cleavage on various functions of $\mathrm{HRG}$, an antibody-based detection method was developed. As the N-terminal domains of HRG (i.e. the two cystatin-like domains, N1 and N2) are relatively resistant to proteases [16] and most plasmin-cleaved fragments of HRG are held together by the N1N2 domain under non-reducing conditions (see Figures 1 and 2), the HRG-4 N1N2-domain-specific antibody was used to detect intact and plasmin-cleaved HRG in various assays. Western blot analysis under reducing conditions identified several bands, indicating a stepwise reduction in the molecular mass of the N-terminus of HRG following plasmin cleavage (Figure 3A; Bands 1-4). These results confirm that the generation of the lower-molecular-mass bands, and the loss of the higher molecular mass bands, represents the progressive plasmin-mediated cleavage of HRG from the C-terminus. The predicted identity of the N-terminal fragments of HRG under reducing conditions are also shown in Figure 3(A). Furthermore, the HRG-4 antibody effectively detected native intact $(0 \mathrm{~min})$ and plasmin-cleaved (30 and $120 \mathrm{~min}$ at $37^{\circ} \mathrm{C}$ ) $\mathrm{HRG}$ immobilized on ELISA wells to a similar extent (Figure 3B). This implies that, under native conditions, the epitope on HRG recognized by the HRG-4 antibody is not sensitive to plasmin cleavage. Therefore, this antibody-based detection method provides a very sensitive means to detect intact and extensively plasmin-cleaved HRG.

\section{Plasmin cleavage reduces HRG binding to cell surface HS}

The cleavage of HRG by plasmin has been shown to generate intact domains of HRG that have preserved functional properties $[10,16]$. Although plasmin-cleaved HRG was predominantly used to isolate the different domains of HRG and to characterize the functions of each domain in isolation from the rest of the molecule [10,16-18], plasmin cleavage can potentially play a physiological role in regulating the normal function of HRG by modulating HRG binding to various ligands. HRG binding to cell surface HS has been shown to play an important role in regulating growth factor binding to HS [23], as well as in tethering plasminogen to the cell surface $[12,14]$. Thus the effect of plasmin cleavage on HRG binding to cell surface HS was initially examined using viable $\mathrm{CHO}-\mathrm{K} 1$ cells as the model cell line [21]. As shown in Figure 4(A), $100 \mu \mathrm{g} / \mathrm{ml}$ HRG bound strongly to viable CHO$\mathrm{K} 1$ cells and showed no detectable binding to the pgsA-745 GAG-deficient $\mathrm{CHO}$ cell line, indicating that HRG binding to CHO-K1 cells is mediated via cell surface GAGs, such as HS [21]. HRG treated with plasmin at $37^{\circ} \mathrm{C}$ for 0,30 and $120 \mathrm{~min}$ was used to represent intact HRG, HRG that has been cleaved predominately at position $\mathrm{Arg}^{421}$ or extensively cleaved HRG respectively. Strikingly, HRG binding to cell surface HS was reduced by $>50 \%$ when $\mathrm{HRG}$ was treated with plasmin for either 30 or $120 \mathrm{~min}$ at $37^{\circ} \mathrm{C}$ (Figure 4B). These results suggest that plasmin cleavage can potentially destroy the HS-binding site and/or modify the conformation of HRG to reduce HRG binding to cell surface HS. It is worth noting that initial $\left(30 \mathrm{~min}\right.$ at $\left.37^{\circ} \mathrm{C}\right)$ or extensive $\left(120 \mathrm{~min}\right.$ at $\left.37^{\circ} \mathrm{C}\right)$ plasmin cleavage of HRG had a similar level of inhibitory effect (approx. $55 \%$ ) on HRG binding 

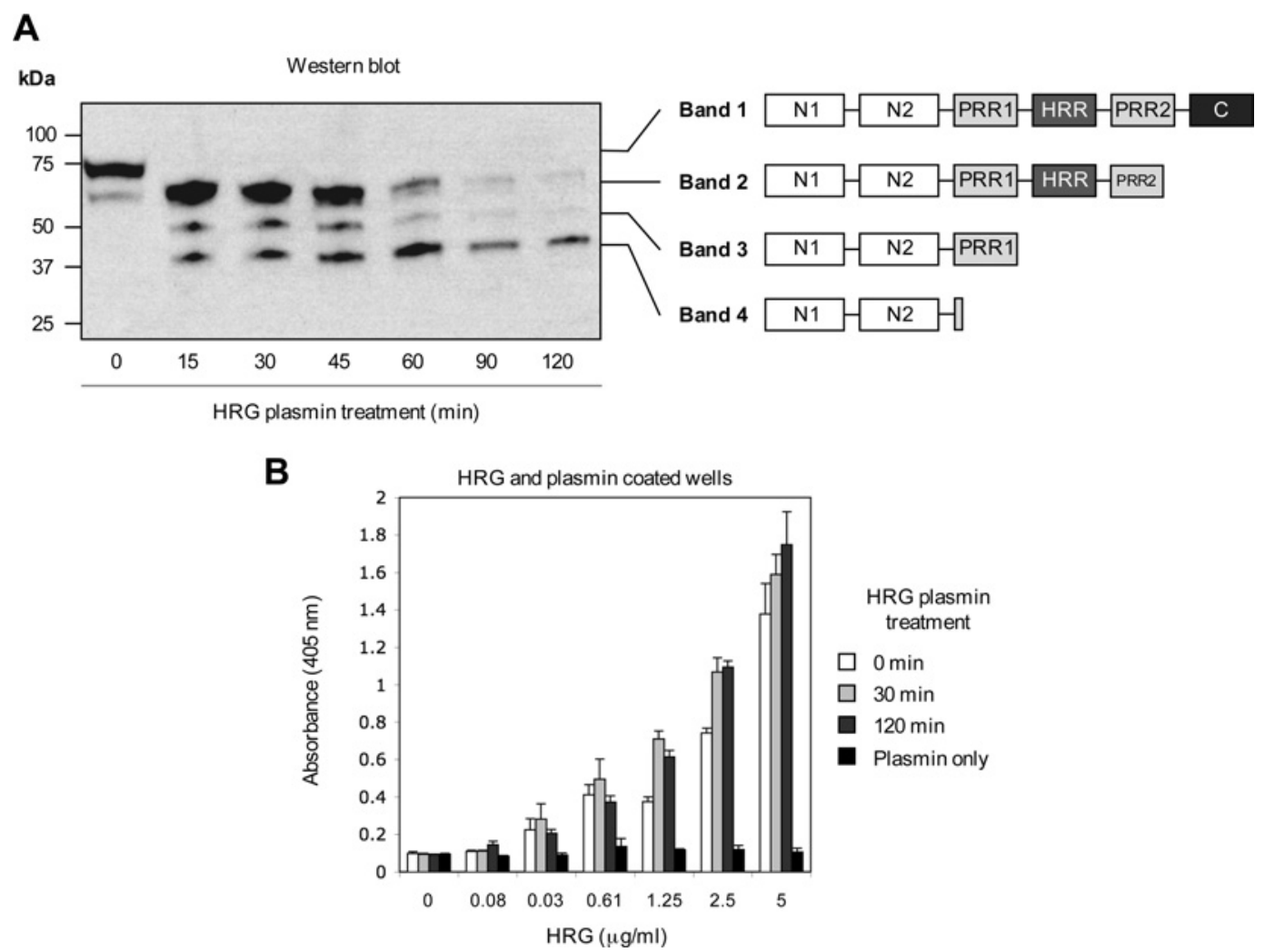

Figure 3 Analysis of plasmin-cleaved HRG using a monoclonal antibody specific for the N1N2 domain

(A) Western blot analysis of the proteolysis of $300 \mathrm{ng}(300 \mu \mathrm{g} / \mathrm{ml})$ HRG by $30 \mathrm{ng}(30 \mu \mathrm{g} / \mathrm{ml})$ plasmin at $37^{\circ} \mathrm{C}$ for 0 to $120 \mathrm{~min}$ using the HRG-4 N1N2-domain-specific antibody. The predicted identity of each N-terminal fragment of HRG under reducing conditions is shown on the right (Bands 1-4). (B) Analysis of the ability of $0.6 \mathrm{ng} / \mathrm{ml}$ HRG-4 N1N2-domain specific antibody, to bind to ELISA wells pre-coated with various concentrations ( 0.08 to $5 \mu \mathrm{g} / \mathrm{ml}$ ) of intact HRG (white bars, 0 min) and plasmin-cleaved HRG for 30 and 120 min (light grey and dark grey bars respectively) at $37^{\circ} \mathrm{C}$. Plasmin alone is included as a negative control (black bars). Error bars represent the S.E.M. over three replicates.

to $\mathrm{CHO}-\mathrm{K} 1$ cells (Figure 4B), indicating that a single plasmin cleavage at position $\mathrm{Arg}^{421}$ is adequate to significantly reduce HRG binding to cell surface HS and further plasmin cleavage had no additional effect. Furthermore, the presence of heparin $(12.5 \mathrm{kDa}, 100 \mu \mathrm{g} / \mathrm{ml})$ completely abolished the ability of intact, as well as plasmin-cleaved HRG, to bind to CHO-K1 cells (Figure 4B), indicating that both intact and plasmin-cleaved HRG can still bind to heparin, which competes for cell surface HS binding.

Previous studies have demonstrated that the binding of HRG to cell surfaces can be potentiated by the presence of $\mathrm{Zn}^{2+}[21,24]$ or by a low $\mathrm{pH}$ [14]. Therefore, the ability of plasmin-cleaved HRG to bind to CHO-K1 cells in the presence of $\mathrm{Zn}^{2+}$ or at a acidic $\mathrm{pH}$ was also investigated. Consistent with previous studies, the presence of physiological concentrations of $\mathrm{Zn}^{2+}(20 \mu \mathrm{M})$ or pH 6.6 enhanced the binding of HRG to cell surface HS (Figure 4C). Interestingly, plasmin treatment (30 and $120 \mathrm{~min}$ at $37^{\circ} \mathrm{C}$ ) not only reduced HRG binding to $\mathrm{CHO}-\mathrm{K} 1$ cells, but also abolished the ability of $\mathrm{Zn}^{2+}$ or acidic $\mathrm{pH}$ to enhance HRG binding (Figure 4C), suggesting that an intact molecule is required for $\mathrm{HRG}$ to respond to regulatory factors such as $\mathrm{Zn}^{2+}$ and $\mathrm{pH}$. Thus plasmin cleavage can potentially inhibit the ability of HRG to function as a $\mathrm{pH}$ and $\mathrm{Zn}^{2+}$ sensor in response to tissue injury.

In additional experiments, the ability of intact and plasmincleaved HRG to bind to necrotic Jurkat T-cells was also examined. In contrast with cell surface HS binding, plasmin-mediated cleavage significantly enhanced the binding of HRG to necrotic cells (Figure 4D). These results suggest that plasmin cleavage at sites of tissue injury may potentiate HRG binding to necrotic cells. Moreover, consistent with the results of Jones et al. [25], the interaction between HRG and necrotic cells is likely to be independent of cell surface HS as, despite plasmin cleavage affecting the binding of HRG to cell surface HS on viable cells, plasmin cleavage had no inhibitory effect on HRG binding to necrotic cells.

\section{Plasmin cleavage may modulate the ability of HRG to regulate the plasminogen/plasmin system}

HRG has been shown to bind to plasminogen in a number of studies [9-12,14] and to modulate the activation of plasminogen into plasmin $[10,12]$. The ability of HRG to tether plasminogen to GAG-coated surfaces has also been proposed to play an important role in facilitating plasminogen activation [12,14]. As HRG itself is sensitive to plasmin cleavage, activation of plasminogen into plasmin may in turn promote the generation of plasmincleaved HRG and alter the ability of HRG to regulate the plasminogen/plasmin system. Therefore the effect of plasmin cleavage on the binding of HRG to plasminogen was initially investigated. Unlike cell surface HS binding, initial plasmin cleavage $\left(30 \mathrm{~min}\right.$ at $\left.37^{\circ} \mathrm{C}\right)$ markedly enhanced HRG binding to plasminogen immobilized on ELISA wells, whereas extensive plasmin cleavage $\left(120 \mathrm{~min}\right.$ at $\left.37^{\circ} \mathrm{C}\right)$ of $\mathrm{HRG}$ resulted in plasminogen binding returning to control levels (Figure 5A). These results suggest that a single plasmin cleavage at $\mathrm{Arg}^{421}$ may alter the conformation of the molecule and expose C-terminal lysine residues to aid plasminogen binding. In contrast, extensive plasmin cleavage may further modify the conformation of HRG 
A

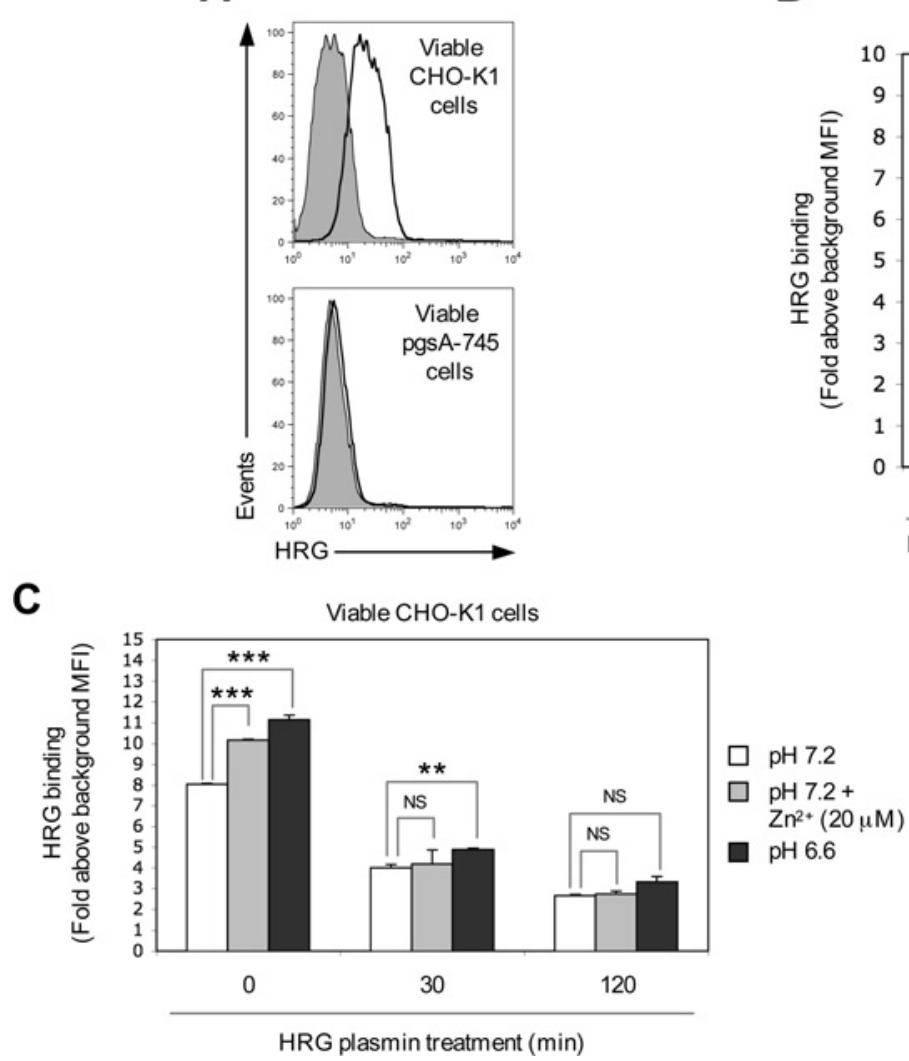

B

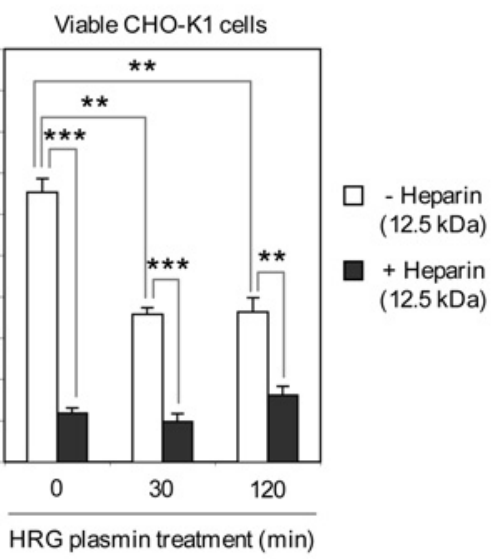

D

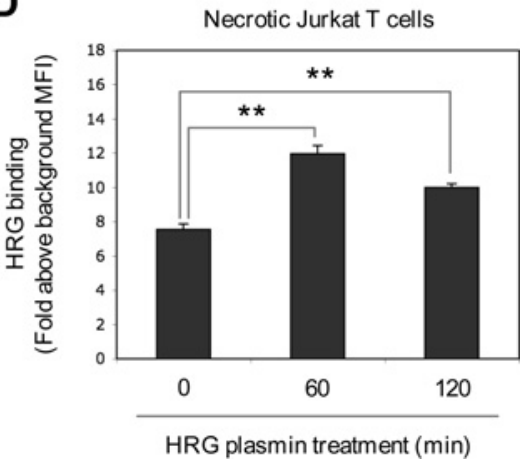

Figure 4 Plasmin cleavage reduces the ability of HRG to bind to cell surface HS but enhances HRG binding to necrotic cells

HRG $(100 \mu \mathrm{g} / \mathrm{ml})$ was subjected to plasmin cleavage and its binding to cell surface $\mathrm{HS}$ or necrotic cells then assessed. (A) Ability of $100 \mu \mathrm{g} / \mathrm{ml}$ intact HRG to bind to viable CHO-K1 cells and a GAG-deficient CHO cell line (pgsA-745) as detected by flow cytometry using an anti-human HRG antibody (HRG-4) and a FITC-conjugated secondary antibody. Representative flow cytometry histograms are shown. The filled histograms represent primary antibody only and secondary antibody only controls. Open histograms represent HRG binding. (B and $\mathbf{C}$ ) Binding of intact (0 min) or plasmin-cleaved HRG (30 and 120 min) to viable CH0-K1 cells in (B) the presence (black bars) or absence (white bars) of heparin and (C) $\mathrm{Zn}^{2+}$ (grey bars) or acid pH (pH 6.6; black bars). (D) Ability of intact ( 0 min) or plasmin-cleaved HRG (30 and $120 \mathrm{~min}$ ) to bind to heat-induced necrotic Jurkat T cells ( $\left.56^{\circ} \mathrm{C}, 30 \mathrm{~min}\right)$. HRG binding in (B-D) was analysed by flow cytometry using the HRG-4 anti-(human HRG) antibody and a PE-conjugated secondary antibody. Results are expressed as fold binding above MFI (median fluorescence intensity). Error bars represent the S.E.M. from three replicates. ${ }^{\star \star} P<0.01 ;{ }^{\star \star \star} P<0.001$; NS, not significant.

and/or remove $\mathrm{C}$-terminal lysine residues to abolish the enhanced plasminogen binding induced by initial plasmin cleavage.

To examine the effect of plasmin cleavage on the ability of HRG to tether plasminogen to GAG-coated surfaces, intact (0 min) or plasmin-cleaved ( 30 and $120 \mathrm{~min}$ at $37^{\circ} \mathrm{C}$ ) HRG was either pre-coated on heparin-coated plates, prior to assessing binding of plasminogen (Figure 5B), or was incubated simultaneously with plasminogen on heparin-coated wells (Figure 5C). As expected, plasminogen binding to heparin-coated wells was markedly enhanced by intact HRG using either binding procedure (Figures 5B and 5C). Surprisingly, plasmin cleavage had minimal effect on the ability of HRG to tether plasminogen to the heparincoated wells (Figure 5B and 5C), indicating that both intact and plasmin-cleaved HRG can enhance the binding of plasminogen to GAG-coated surfaces.

\section{Regulation of plasmin-mediated cleavage of HRG by heparin, $\mathrm{Zn}^{2+}$ and $\mathrm{pH}$}

As plasmin cleavage can regulate various functions of $H R G$, factors that may modulate the proteolysis of HRG by plasmin were further examined. The binding of growth factors and chemokines such as FGF (fibroblast growth factor) [26] and eotaxin [27] to heparin/HS has been shown to protect these molecules from plasmin-mediated degradation. Thus the effect of heparin on the proteolytic cleavage of HRG by plasmin was investigated to evaluate the sensitivity of HRG to plasmin cleavage when bound to cell surface HS or free heparin. As shown in Figure 6(A), heparin $(12.5 \mathrm{kDa}, 2$ and $10 \mu \mathrm{g} / \mathrm{ml})$ alone did not interfere with plasmin activity as measured by the cleavage of the chromogenic substrate $N$-( $p$-tosyl)-Gly-Pro-Lys. However, the presence of heparin attenuated plasmin-mediated cleavage of HRG, as indicated by the lack of lower-molecular-mass N-terminal fragments of HRG (Figure 6B). These results suggest that the binding of HRG to heparin can protect HRG from plasmin cleavage, possibly by masking exposed plasmin cleavage sites.

Furthermore, an increase in the local concentration of $\mathrm{Zn}^{2+}$, and a decrease in $\mathrm{pH}$, at sites of tissue injury have been proposed to regulate various functions of $\mathrm{HRG}$, such as $\mathrm{HRG}$ tethering plasminogen to cell surfaces [14] and HRG exerting antimicrobial effects $[20,28]$. Thus the effect of $\mathrm{Zn}^{2+}$ and acidic $\mathrm{pH}$ on the proteolysis of HRG by plasmin was investigated. Acidic $\mathrm{pH}$, in particular $\mathrm{pH}$ 6.0, and to a much lesser extent the presence of 10 and $20 \mu \mathrm{M} \mathrm{Zn}^{2+}$ ions, reduced the enzymatic activity of plasmin against the chromogenic substrate (Figure 6C), but also resulted in a substantial reduction in plasmin-mediated cleavage of $\mathrm{HRG}$ (Figure 6D). These results suggest that an increase in the local $\mathrm{Zn}^{2+}$ concentration and/or a decrease in $\mathrm{pH}$ may delay plasminmediated cleavage of HRG by directly reducing plasmin activity but, in the case of $\mathrm{Zn}^{2+}$, may also render HRG less susceptible 


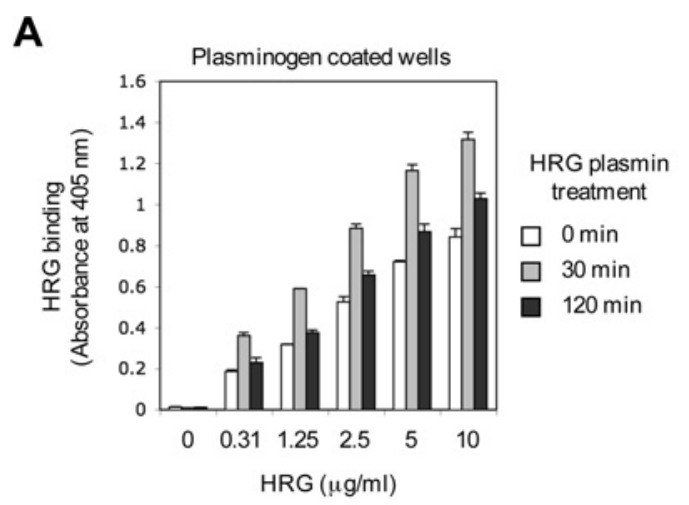

B

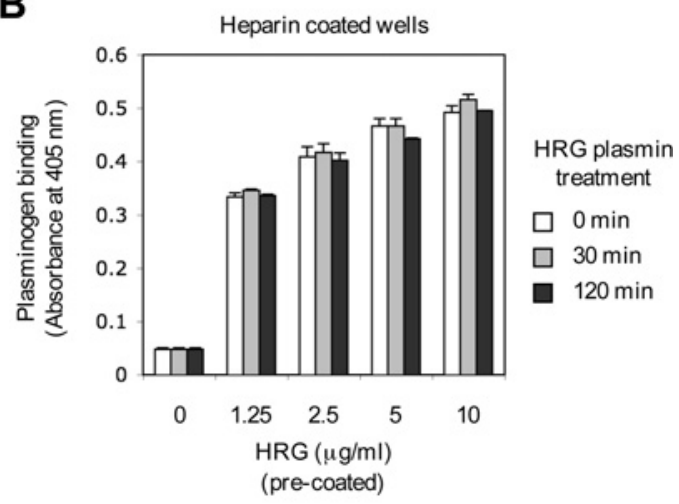

C

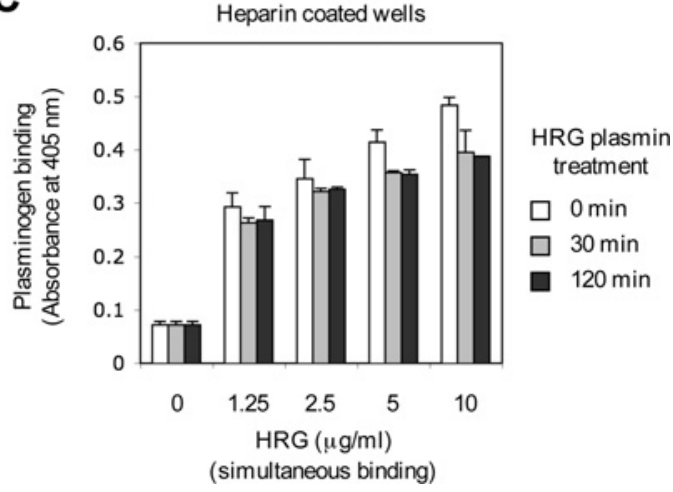

Figure 5 Plasmin cleavage enhances HRG binding to plasminogen but had no effect on HRG-mediated tethering of plasminogen to immobilized heparin

(A) Effect of plasmin cleavage $\left(0,30\right.$ and 120 min at $\left.37^{\circ} \mathrm{C}\right)$ on HRG binding to immobilized human plasminogen measured by ELISA using wells pre-coated with $1 \mu \mathrm{g} / \mathrm{ml}$ of human plasminogen. Error bars represent the S.E.M. for three replicates. (B and $\mathbf{C}$ ) Analysis of the ability of intact ( 0 min) and plasmin-cleaved ( 30 and 120 min at $37^{\circ} \mathrm{C}$ ) HRG to tether human plasminogen to heparin-coated ELISA wells by (B) pre-coating heparin-coated wells with HRG prior to assessing binding of human plasminogen $(5 \mu \mathrm{g} / \mathrm{ml}$ ) or (C) by simultaneous incubation of HRG and human plasminogen $(5 \mu \mathrm{g} / \mathrm{ml})$ with heparin-coated wells. ELISA wells were pre-coated with $10 \mu \mathrm{g} / \mathrm{ml}$ ExtrAvidin ${ }^{\circledR}$ and $10 \mu \mathrm{g} / \mathrm{ml}$ biotinylated heparin and then analysed for plasminogen binding by ELISA under the different conditions. Error bars represent the range of duplicate samples.

to plasmin cleavage, possibly via a conformational change in the HRG molecule.

\section{DISCUSSION}

On the basis of the modular structure of HRG and the ability of HRG to bind to a variety of different ligands [6], it has been proposed that HRG may function as an adaptor molecule that interacts with multiple ligands simultaneously via several independent binding sites [16]. Thus HRG can potentially regulate numerous biological processes such as cell adhesion, angiogenesis, coagulation, fibrinolysis and clearance of immune complexes, necrotic cells and pathogens. Importantly, the functions of HRG are often regulated by $\mathrm{pH}$ and $\mathrm{Zn}^{2+}$ [6], these factors modulating HRG activity at sites of tissue injury when local $\mathrm{pH}$ decreases $[29,30]$ or when local $\mathrm{Zn}^{2+}$ concentrations increase due to the release of $\mathrm{Zn}^{2+}$ from degranulating platelets [31]. Apart from local $\mathrm{Zn}^{2+}$ concentrations and $\mathrm{pH}$, it has been suggested that proteolytic degradation of HRG may be required for HRG to exert its antiangiogenic activity [19]. Although the ability of proteases such as plasmin and kallikrein to cleave HRG was initially reported by Smith et al. [15], the results presented in this study provide the first detailed analysis of the proteolytic cleavage of human HRG by plasmin and demonstrate the potential effects of plasminmediated cleavage on the functional activity of HRG (summarized in Figure 7).

In contrast with kallikrein-mediated cleavage of HRG, which degrades HRG extensively and rapidly [15], HRG is cleaved at specific sites by plasmin, generating distinct fragments that are relatively resistant to further plasmin cleavage, with the exception that an internal $\sim 20 \mathrm{kDa}$ fragment is degraded following prolonged plasmin treatment (Figure 1). Most importantly, plasmin cleavage occurs between the various domains of HRG, which may preserve the function of these domains (e.g. the N1N2, HRR and C-terminal domain) (Figures 1 and 2). However, unlike the closely related cystatin superfamily member high-molecularmass kininogen [32,33], the majority of the plasmin-generated fragments of HRG remain bound to the N1N2 domain of HRG via disulfide bridges (Figures 1 and 2), suggesting that plasmin cleavage alone is unlikely to release various potentially active fragments of HRG. Nevertheless, the results from the present study suggest that plasmin cleavage alone can modulate the ability of HRG to bind to various ligands, possibly by altering the conformation of HRG and/or disrupting ligand binding sites. We show a single plasmin cleavage at $\mathrm{Arg}^{421}$ on $\mathrm{HRG}$ was sufficient to reduce HRG binding to cell surface $\mathrm{HS}$ by over $50 \%$ (Figure $4 \mathrm{~B}$ ). As the $\mathrm{Arg}^{421}$ plasmin cleavage site is located distantly from the proposed HS/heparin-binding sites on HRG (i.e. the N1N2 domain [21] and HRR [34] domain of HRG), the decrease in HRG binding to cell surface HS following plasmin cleavage at a single site is likely to be the result of a conformational change in HRG, rather than being due to a direct disruption of the HS/heparin-binding sites. It is worth noting that plasmin cleavage only partially reduced the binding of HRG to HS (Figure 4B), suggesting that one or both HS/heparin-binding sites on HRG can remain partly functional following plasmin cleavage. However, some indirect evidence in the present study suggests that plasmin cleavage is likely to modify the function of the HS/heparinbinding site located in the HRR rather than that in the N1N2 domain of HRG. For example, excessive plasmin cleavage, which preserved the integrity of the N1N2 domain but degraded the predicted HRR fragment of HRG (Figure 1 and 2), resulted in no further reduction in HRG binding to cell surface HS compared with HRG that was cleaved predominately at $\mathrm{Arg}^{421}$ (Figure 4B). Furthermore, plasmin cleavage also rendered HRG unresponsive to acidic $\mathrm{pH}$ or $\mathrm{Zn}^{2+}$ (Figure $4 \mathrm{C}$ ), which are factors known to potentiate the HS/heparin-binding properties of the HRR [34], but not the N1N2 domain of HRG [21]. Thus the residual binding of HRG to cell surface HS and heparin following plasmin cleavage is probably mediated via the N1N2 domain of HRG.

As $\mathrm{HS}$ binding is required for HRG to regulate various biological processes [6,8], the ability of plasmin cleavage to modulate HRG binding to HS is likely to have a major impact 
A

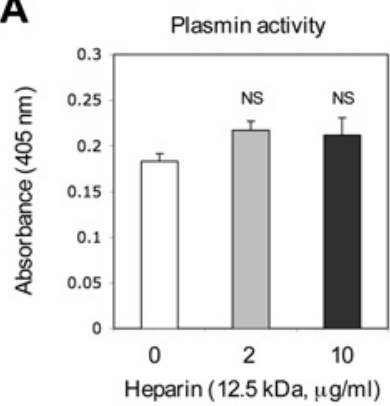

C

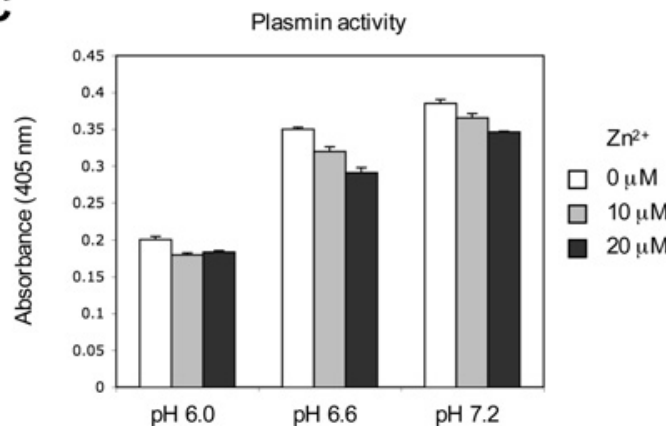

B

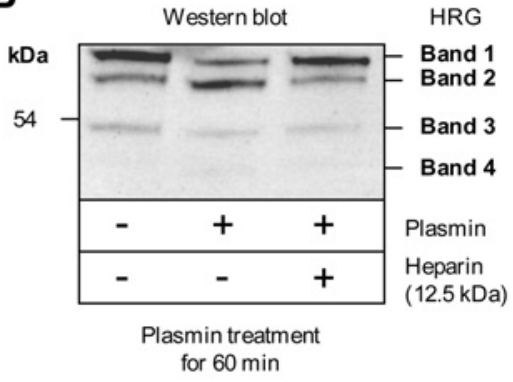

D

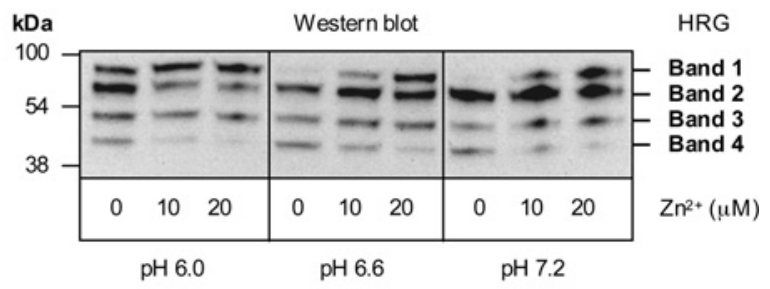

Figure 6 The presence of heparin, $\mathrm{Zn}^{2+}$ and acidic $\mathrm{pH}$ delays proteolytic cleavage of HRG by plasmin

(A) Effect of heparin $(12.5 \mathrm{kDa}, 2$ or $10 \mu \mathrm{g} / \mathrm{ml})$ on plasmin enzymatic activity $(2 \mu \mathrm{g} / \mathrm{ml})$ as measured by the cleavage of the chromogenic substrate $\mathrm{N}$-( $\left(\mathrm{p}\right.$-tosyl)-Gly-Pro-Lys $(1 \mathrm{mg} / \mathrm{ml})$ at $37^{\circ} \mathrm{C}$ for $60 \mathrm{~min}$. Error bars represent the S.E.M. for three replciates. NS, not significant. (B) Western blot analysis of the proteolysis of $300 \mathrm{ng} \mathrm{HRG}(30 \mu \mathrm{g} / \mathrm{ml})$ by $60 \mathrm{ng} \mathrm{plasmin}(6 \mu \mathrm{g} / \mathrm{ml})$ at $37^{\circ} \mathrm{C}$ for 60 min in the presence $(+)$ or absence $(-)$ of heparin $(12.5 \mathrm{kDa}, 50 \mathrm{ng}, 5 \mu \mathrm{g} / \mathrm{ml})$. (C) Effect of pH and variuous concentrations of $\mathrm{Zn}^{2+}$ on plasmin enzymatic activity $(2 \mu \mathrm{g} / \mathrm{ml})$ as measured by the cleavage of the chromogenic substrate $\mathrm{N}$-(p-tosyl)-Gly-Pro-Lys $(1 \mathrm{mg} / \mathrm{ml})$ at $37^{\circ} \mathrm{C}$ for $60 \mathrm{~min}$. Error bars represent the S.E.M. for three replicates. (D) Western blot analysis of the proteolysis of $300 \mathrm{ng} \mathrm{HRG}(30 \mu \mathrm{g} / \mathrm{ml})$ by $60 \mathrm{ng}$ plasmin $(6 \mu \mathrm{g} / \mathrm{ml})$ at $37^{\circ} \mathrm{C}$ for $60 \mathrm{~min}$ in the presence of 0,10 or $20 \mu \mathrm{M} \mathrm{Zn}{ }^{2+}$ and at different pH (pH 6.0, 6.6 or 7.2). N-terminal fragments of HRG in (B) and (D) were analysed by SDS/PAGE under reducing conditions and were detected using the HRG-4 anti-(human HRG) antibody. Predicted N-terminal fragments of HRG (Bands 1-4) are as in Figure 3(A).

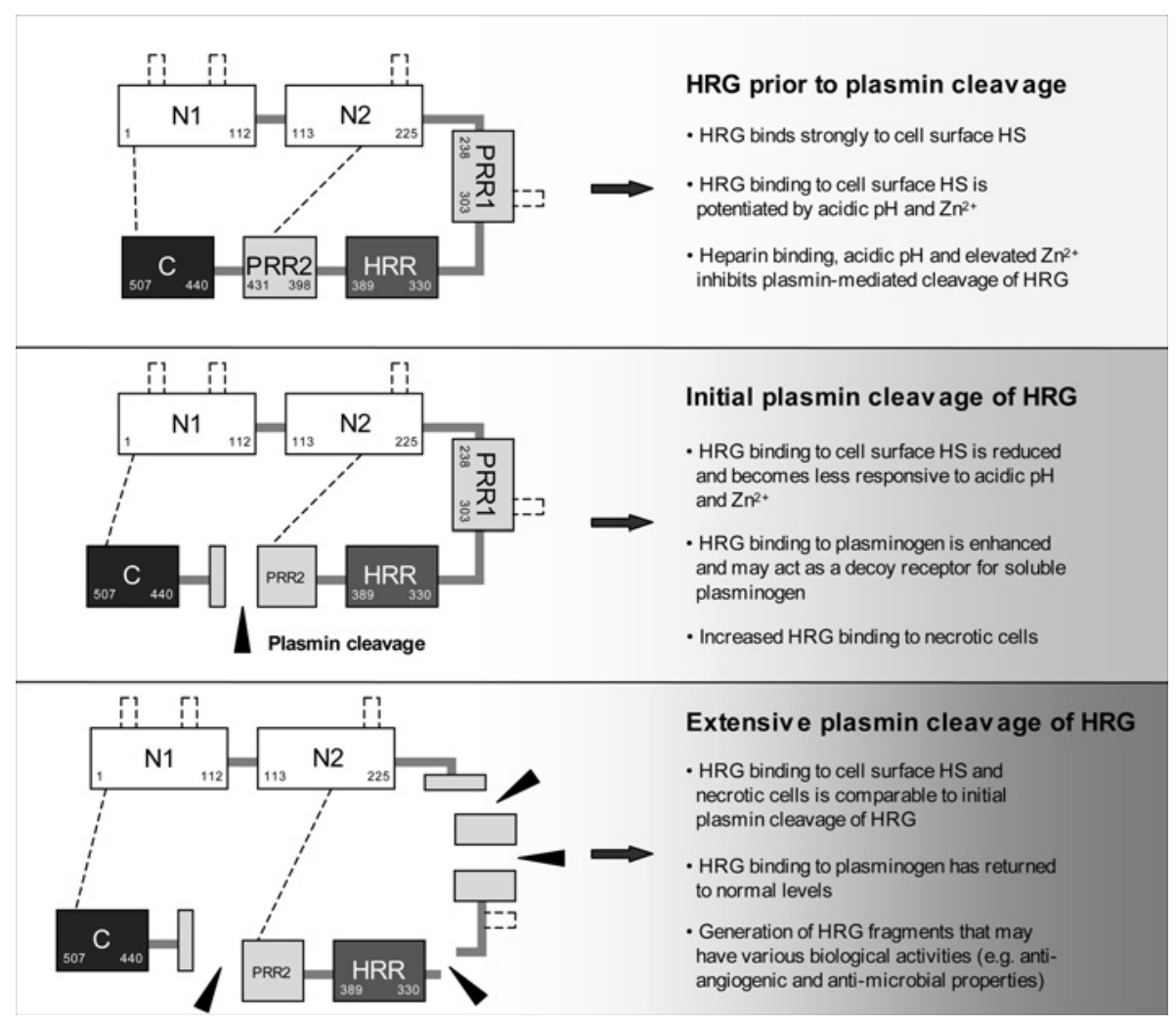

Figure 7 Regulation of HRG function by plasmin-mediated proteolytic cleavage 
on the function of HRG. For example, plasmin cleavage may affect the ability of HRG to compete with other HS/heparinbinding proteins, such as FGF-2 or heparanase, from interacting with cell surface HS and the ECM. Previous studies have also demonstrated that HRG can aid the activation of plasminogen to plasmin by tethering plasminogen to GAG-presenting surfaces $[12,14]$. Thus proteolytic cleavage of HRG by plasmin may act as a negative feedback mechanism to limit plasminogen activation by reducing the amount of intact $H R G$ that can efficiently tether plasminogen to GAG-presenting surfaces. Interestingly, in a similar manner to plasmin-cleaved fibrin [4], initial plasmin cleavage enhanced the binding of HRG to plasminogen (Figure 5A), possibly via the exposure of a C-terminal lysine residue. This is consistent with previous studies where "plasminclipped' rabbit HRG also shows an enhancement in plasminogen binding compared with intact HRG [10]. As plasmincleaved HRG retained the ability to bind plasminogen (Figure 5A), but interacted with cell surface HS less efficiently (Figure 4B), plasmin-cleaved HRG may also act as a decoy receptor for plasminogen, which could compete with intact HRG, or other plasminogen receptors, for plasminogen binding to cell surfaces. Surprisingly, plasmin cleavage did not have any apparent effect on the ability of HRG to tether plasminogen to heparincoated surfaces (Figure 5B and 5C), although this may be due to the high density of immobilized heparin masking the partial loss in cell surface HS binding exhibited by plasmin-cleaved HRG.

As mentioned above, several studies have suggested that the HRR of HRG (in particular peptide fragments derived from the HRR of HRG) exhibit anti-angiogenic [17-19,35,36], anti-microbial $[20,28,37]$ and endotoxin-neutralizing properties [38]. Interestingly, unlike in rabbit HRG, a potential plasmin cleavage site at $\operatorname{Arg}^{360}$ within the HRR of human HRG may allow the release of a HRG fragment in the absence of disulfide cleavage (corresponding to amino acid residues 322-360 following plasmin cleavage at $\operatorname{Arg}^{321}$ and $\mathrm{Arg}^{360}$ ) that is similar to the well-characterized HRG-derived heparin-binding/antiangiogenic peptide, HRGP330 (HRG residues 330-364) [3436]. Although this predicted HRR fragment of HRG was not apparent in this study when plasmin-cleaved HRG was analysed under both non-reducing and reducing conditions (Figure 1), further investigation is needed to determine whether the release of the HRR of HRG requires both proteolytic and disulfide cleavage. Interestingly, the unpublished observations discussed in Rydengard et al. [20] suggest that elastase is capable of digesting HRG and may generate peptides derived from the HRR of HRG.

The experimental results in the present study also demonstrate that factors such as heparin, $\mathrm{Zn}^{2+}$ and $\mathrm{pH}$, may co-operatively regulate the ability of plasmin to cleave HRG (Figure 6). Consistent with a previous study by Smith et al. [15], the binding of heparin by HRG reduced the sensitivity of HRG to plasmin cleavage (Figure 6B). Similarly, acidic $\mathrm{pH}$ and the presence of $\mathrm{Zn}^{2+}$ directly inhibited plasmin activity (Figure 6C), as well as substantially reducing the cleavage of HRG by plasmin (Figure 6D). Indeed, the ability of $\mathrm{Zn}^{2+}$ to inhibit plasmin activity has been shown previously to abolish the proteolytic cleavage of fibrinogen by plasmin [39]. In addition, under conditions of tissue injury when the local concentration of $\mathrm{Zn}^{2+}$ is elevated [31] and the $\mathrm{pH}$ is acidic [29,30], HRG can bind more effectively to cell surface HS [14,21], thereby masking plasmin cleavage sites and possibly further delaying the proteolytic cleavage of HRG by plasmin. On the basis of these results, the ability of acidic $\mathrm{pH}$ and elevated $\mathrm{Zn}^{2+}$ levels to reduce plasmin-mediated cleavage of $\mathrm{HRG}$ represents a novel indirect mechanism of regulating the function of HRG.
It is worth noting that as intact HRG was used in most of the published studies that define HRG functions, proteolytic cleavage is unlikely to be essential for HRG to perform its role in many biological processes. However, disassembling the modular domain structure of HRG through plasmin-mediated cleavage, and possibly inter-domain disulfide bond cleavage may modulate the functional activity of HRG in multiple biological systems. For example, under normal physiological conditions, a large proportion of HRG may form high-affinity complexes with ligands, such as with IgG and plasminogen in plasma and with HS present on cell surfaces and in the ECM. These complexes can potentially sequester HRG away from interacting with other ligands or inducing an anti-angiogenic, anti-microbial or endotoxin-neutralizing effect via the HRR of HRG. Therefore, the combination of proteolytic and disulfide cleavage may release fragments of $\mathrm{HRG}$ containing different domains that can perform independent functions. Alternatively, the release of differently cleaved fragments may also abolish the ability of HRG to function as an adaptor molecule, such as by tethering plasminogen to GAGpresenting surfaces $[12,14]$.

In summary, the experimental results in the present study demonstrate that various functions of HRG can be regulated by plasmin cleavage, which may in turn affect the ability of HRG to modulate the plasminogen/plasmin system. As proteolytically cleaved HRG can persist in the circulation [15], cleavage of HRG by proteases such as plasmin may provide an elegant means of regulating the multi-functional properties of $\mathrm{HRG}$, rather than simply controlling the turnover of the protein. Further investigations are needed to examine the role of plasmin cleavage, as well as proteolytic cleavage by other proteases, such as kallikrein and elastase, in regulating the function of HRG in immunity, tumour progression and vascular biology.

\section{AUTHOR CONTRIBUTION}

Ivan Poon designed research, performed research, analysed data and wrote the paper. Anna-Karin Olsson contributed new reagents. Mark Hulett and Christopher Parish designed research, analysed results and wrote the paper.

\section{ACKNOWLEDGEMENTS}

We thank Dr Allison Jones and Dr Craig Freeman (The John Curtin School of Medical Research, Australian National University, Canberra, Australia) for purified human plasmaderived HRG, human plasminogen and biotinylated heparin. This research has been facilitated by access to the Australian Proteome Analysis Facility established under the Australian Government's Major National Research Facilities program.

\section{FUNDING}

This work was supported by the Australian National Health and Medical Research Council [grant numbers 209618, 455395 and 418008].

\section{REFERENCES}

1 Cesarman-Maus, G. and Hajjar, K. A. (2005) Molecular mechanisms of fibrinolysis. Br. J. Haematol. 129, 307-321

2 Nielsen, L. S., Hansen, J. G., Skriver, L., Wilson, E. L., Kaltoft, K., Zeuthen, J. and Dano, K. (1982) Purification of zymogen to plasminogen activator from human glioblastoma cells by affinity chromatography with monoclonal antibody. Biochemistry 21, 6410-6415

3 Pennica, D., Holmes, W. E., Kohr, W. J., Harkins, R. N., Vehar, G. A., Ward, C. A., Bennett, W. F., Yelverton, E., Seeburg, P. H., Heyneker, H. L. et al. (1983) Cloning and expression of human tissue-type plasminogen activator cDNA in. E coli. Nature 301, 214-221

4 Fleury, V., Loyau, S., Lijnen, H. R., Nieuwenhuizen, W. and Angles-Cano, E. (1993) Molecular assembly of plasminogen and tissue-type plasminogen activator on an evolving fibrin surface. Eur. J. Biochem. 216, 549-556

5 Montuori, N., Rossi, G. and Ragno, P. (1999) Cleavage of urokinase receptor regulates its interaction with integrins in thyroid cells. FEBS Lett. 460, 32-36 
6 Jones, A. L., Hulett, M. D. and Parish, C. R. (2005) Histidine-rich glycoprotein: a novel adaptor protein in plasma that modulates the immune, vascular and coagulation systems. Immunol. Cell Biol. 83, 106-118

7 Sorensen, C. B., Krogh-Pedersen, H. and Petersen, T. E. (1993) Determination of the disulphide bridge arrangement of bovine histidine-rich glycoprotein. FEBS Lett. $\mathbf{3 2 8}$ 285-290

8 Blank, M. and Shoenfeld, Y. (2008) Histidine-rich glycoprotein modulation of immune/autoimmune, vascular, and coagulation systems. Clin. Rev. Allergy Immunol. 34, 307-312

9 Lijnen, H. R., Hoylaerts, M. and Collen, D. (1980) Isolation and characterization of a human plasma protein with affinity for the lysine binding sites in plasminogen. Role in the regulation of fibrinolysis and identification as histidine-rich glycoprotein. J. Biol. Chem. 255, 10214-10222

10 Borza, D. B. and Morgan, W. T. (1997) Acceleration of plasminogen activation by tissue plasminogen activator on surface-bound histidine-proline-rich glycoprotein. J. Biol. Chem. 272, 5718-5726

11 Saez, C. T., Jansen, G. J., Smith, A. and Morgan, W. T. (1995) Interaction of histidineproline-rich glycoprotein with plasminogen: effect of ligands, $\mathrm{pH}$, ionic strength, and chemical modification. Biochemistry 34, 2496-2503

12 Borza, D. B., Shipulina, N. V. and Morgan, W. T. (2004) Effects of histidine-proline-rich glycoprotein on plasminogen activation in solution and on surfaces. Blood Coagul. Fibrinolysis 15, 663-672

13 Horne, M. K., Goad, J. L., Merryman, P. K. and Cullinane, A. M. (2000) Comparison of the effect of histidine-rich glycoprotein and 6-aminohexanoic acid on plasmin production and fibrinolysis in vitro. Thromb. Res. 99, 179-186

14 Jones, A. L., Hulett, M. D., Altin, J. G., Hogg, P. and Parish, C. R. (2004) Plasminogen is tethered with high affinity to the cell surface by the plasma protein, histidine-rich glycoprotein. J. Biol. Chem. 279, 38267-38276

15 Smith, A., Nuiry, I. and Morgan, W. T. (1985) Proteolysis of histidine-rich glycoprotein in plasma and in patients undergoing thrombolytic therapy. Thromb. Res. 40, 653-661

16 Borza, D. B., Tatum, F. M. and Morgan, W. T. (1996) Domain structure and conformation of histidine-proline-rich glycoprotein. Biochemistry 35, 1925-1934

17 Juarez, J. C., Guan, X., Shipulina, N. V., Plunkett, M. L., Parry, G. C., Shaw, D. E., Zhang, J. C., Rabbani, S. A., McCrae, K. R., Mazar, A. P. et al. (2002) Histidine-proline-rich glycoprotein has potent antiangiogenic activity mediated through the histidine-prolinerich domain. Cancer Res. 62, 5344-5350

18 Donate, F., Juarez, J. C., Guan, X., Shipulina, N. V., Plunkett, M. L., Tel-Tsur, Z., Shaw, D. E., Morgan, W. T. and Mazar, A. P. (2004) Peptides derived from the histidine-proline domain of the histidine-proline-rich glycoprotein bind to tropomyosin and have antiangiogenic and antitumor activities. Cancer Res. 64, 5812-5817

19 Olsson, A. K., Larsson, H., Dixelius, J., Johansson, I., Lee, C., Oellig, C., Bjork, I. and Claesson-Welsh, L. (2004) A fragment of histidine-rich glycoprotein is a potent inhibitor of tumor vascularization. Cancer Res. 64, 599-605

20 Rydengard, V., Olsson, A. K., Morgelin, M. and Schmidtchen, A. (2007) Histidine-rich glycoprotein exerts antibacterial activity. Febs J. 274, 377-389

21 Jones, A. L., Hulett, M. D. and Parish, C. R. (2004) Histidine-rich glycoprotein binds to cell-surface heparan sulfate via its $\mathrm{N}$-terminal domain following $\mathrm{Zn}^{2+}$ chelation. J. Biol. Chem. 279, 30114-30122

22 Rylatt, D. B., Sia, D. Y., Mundy, J. P. and Parish, C. R. (1981) Autorosette inhibition factor: isolation and properties of the human plasma protein. Eur. J. Biochem. 119, 641-646
23 Brown, K. J. and Parish, C. R. (1994) Histidine-rich glycoprotein and platelet factor 4 mask heparan sulfate proteoglycans recognized by acidic and basic fibroblast growth factor. Biochemistry 33, 13918-13927

24 Olsen, H. M., Parish, C. R. and Altin, J. G. (1996) Histidine-rich glycoprotein binding to T-cell lines and its effect on T-cell substratum adhesion is strongly potentiated by zinc. Immunology 88, 198-206

25 Jones, A. L., Poon, I. K., Hulett, M. D. and Parish, C. R. (2005) Histidine-rich glycoprotein specifically binds to necrotic cells via its amino-terminal domain and facilitates necrotic cell phagocytosis. J. Biol. Chem. 280, 35733-35741

26 Saksela, O., Moscatelli, D., Sommer, A. and Rifkin, D. B. (1988) Endothelial cell-derived heparan sulfate binds basic fibroblast growth factor and protects it from proteolytic degradation. J. Cell Biol. 107, 743-751

27 Ellyard, J. I., Simson, L., Bezos, A., Johnston, K., Freeman, C. and Parish, C. R. (2007) Eotaxin selectively binds heparin. An interaction that protects eotaxin from proteolysis and potentiates chemotactic activity in vivo. J. Biol. Chem. 282, 15238-15247

28 Rydengard, V., Shannon, O., Lundqvist, K., Kacprzyk, L., Chalupka, A., Olsson, A. K., Morgelin, M., Jahnen-Dechent, W., Malmsten, M. and Schmidtchen, A. (2008) Histidine-rich glycoprotein protects from systemic Candida infection. PLoS Pathog. 4 e1000116

29 LaManna, J. C. (1996) Hypoxia/ischemia and the pH paradox. Adv. Exp. Med. Biol. 388 283-292

30 Punnia-Moorthy, A. (1987) Evaluation of $\mathrm{pH}$ changes in inflammation of the subcutaneous air pouch lining in the rat, induced by carrageenan, dextran and Staphylococcus aureus . J. Oral Pathol. 16, 36-44

31 Aktulga, A. and Ulutin, O. N.. (1974) Normal human platelet zinc content and its release. In Recent Advances in Basic Research and Clinical Aspects (Ulutin, 0. N. and Jones, J. V., eds), pp. 185-191, Excerpta Medica, Amsterdam

32 Kleniewski, J., Blankenship, D. T., Cardin, A. D. and Donaldson, V. (1992) Mechanism of enhanced kinin release from high molecular weight kininogen by plasma kallikrein after its exposure to plasmin. J. Lab. Clin. Med. 120, 129-139

33 Kleniewski, J. and Donaldson, V. H. (1987) Comparison of human high molecular weight kininogen digestion by plasma kallikrein and by plasmin. A revised method of purification of high molecular weight kininogen. J. Lab. Clin. Med. 109, 469-479

34 Vanwildemeersch, M., Olsson, A. K., Gottfridsson, E., Claesson-Welsh, L., Lindahl, U. and Spillmann, D. (2006) The anti-angiogenic His/Pro-rich fragment of histidine-rich glycoprotein binds to endothelial cell heparan sulfate in a $\mathrm{Zn}^{2+}$-dependent manner. J. Biol. Chem. 281, 10298-10304

35 Dixelius, J., Olsson, A. K., Thulin, A., Lee, C., Johansson, I. and Claesson-Welsh, L. (2006) Minimal active domain and mechanism of action of the angiogenesis inhibitor histidine-rich glycoprotein. Cancer Res. 66, 2089-2097

36 Lee, C., Dixelius, J., Thulin, A., Kawamura, H., Claesson-Welsh, L. and Olsson, A. K. (2006) Signal transduction in endothelial cells by the angiogenesis inhibitor histidine-rich glycoprotein targets focal adhesions. Exp. Cell Res. 312, 2547-2556

37 Kacprzyk, L., Rydengard, V., Morgelin, M., Davoudi, M., Pasupuleti, M., Malmsten, M. and Schmidtchen, A. (2007) Antimicrobial activity of histidine-rich peptides is dependent on acidic conditions. Biochim. Biophys. Acta. 1768, 2667-2680

38 Bosshart, H. and Heinzelmann, M. (2003) Endotoxin-neutralizing effects of histidine-rich peptides. FEBS Lett. 553, 135-140

39 Nowak, P. and Zgirski, A. (2003) Effects of metal ions on activity of plasmin. Biol. Trace Elem. Res. 93, 87-94 


\section{SUPPLEMENTARY ONLINE DATA}

\section{Regulation of histidine-rich glycoprotein (HRG) function via plasmin-mediated proteolytic cleavage}

Ivan K. H. POON ${ }^{\star} \dagger$, Anna-Karin OLSSON $\ddagger$, Mark D. HULETT ${ }^{\star} \dagger^{-1}$ and Christopher R. PARISH*1,2

*The John Curtin School of Medical Research, Australian National University, Canberra, ACT 2601, Australia, † Department of Biochemistry, La Trobe University, Melbourne, SA 3086, Australia, and $\ddagger$ Department of Medical Biochemistry and Microbiology, Uppsala Biomedical Center, Uppsala University, SE-75123 Uppsala, Sweden

\section{Human HRG amino acid sequence}

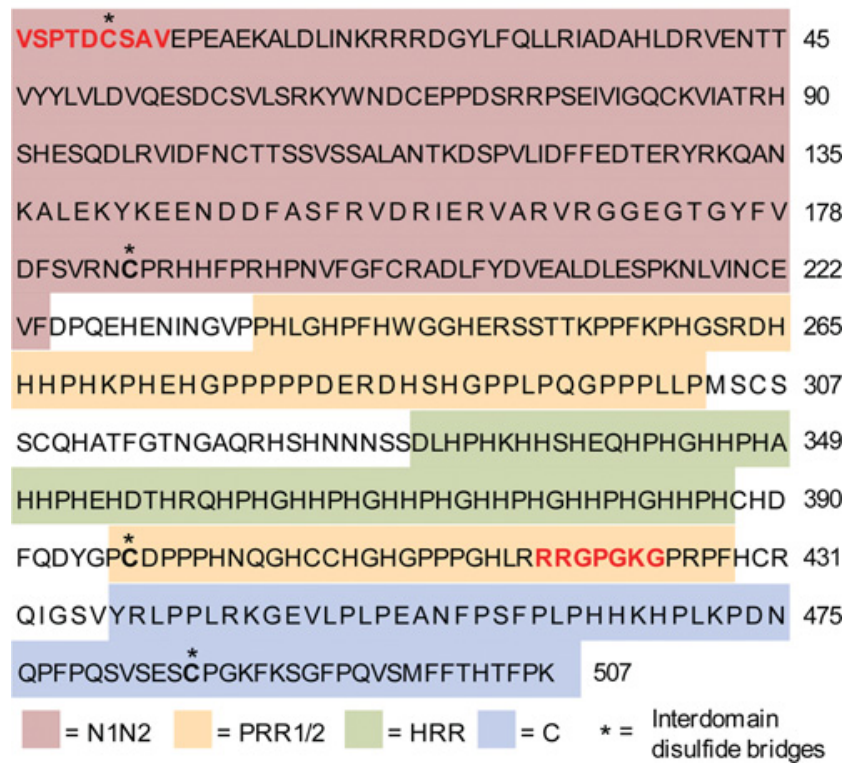

\section{Figure S1 The amino acid sequence of human HRG}

N-terminal amino acid sequencing results acquired from intact and plasmin-cleaved HRG fragments are indicated in red and the domains of HRG are highlighted in different colours. Cysteine residues that mediate interdomain disulfide bridges are highlighted in bold and with asterisks. N1N2, N-terminal domains 1 and 2; PRR 1/2, proline-rich region 1 or 2; HRR, histidine-rich region; C, C-terminal domain.

Received 28 May 2009/5 August 2009; accepted 27 August 2009

Published as BJ Immediate Publication 27 August 2009, doi:10.1042/BJ20090794

1 These authors contributed equally to this work.

2 To whom correspondence should be addressed (email Christopher.Parish@anu.edu.au). 